\title{
Differential Activity of Glucocerebrosidase in Neurons and Astrocytes; Implications for Evaluating Tissue Homogenates derived from Parkinson 's Disease Brains.
}

\author{
Derek Burke \& Simon Heales \\ Enzyme Unit, NIHR BRC Great Ormond Street Hospital Foundation Trust and UCL Great \\ Ormond Street Institute of Child Health, London, UK.
}

Keywords; Glucocerebrosidase, Astrocytes, Neurons, Parkinson's,

Corresponding Author; Professor Simon Heales Enzyme Unit, NIHR BRC Great Ormond Street Hospital Foundation Trust and UCL Great Ormond Street Institute of Child Health, London, UK.

Tel; +44 2078138321

Dear Editor,

Loss of lysosomal glucocerebrosidase (GBA1) activity is a risk factor for developing Parkinson's disease (PD). Whilst GBA1 mutations conveying risk have been characterised, loss of brain enzyme activity has also been reported in brain homogenates derived from patients with idiopathic PD [1]. Currently, the mechanism for this apparent reduction in activity is not known. Since PD is characterised by loss of dopaminergic neurons [2], we considered the possibility that the likely resultant alteration in the glial: neuronal ratio in affected brain regions may be an important factor to consider, i.e. when interpreting GBA1 activity in PD brain homogenates.

To assess out hypothesis, we evaluated the enzymatic activity of GBA1 in human neuronal (SHSY5Y) and astrocytic (1321N1) cell line homogenates. In addition, we assessed the activity of the non-lysosomal enzyme, GBA2, that displays similar substrate specificity to GBA1 and has been shown to be related to GBA1 activity [3]. Furthermore, $\beta$-galactosidase ( $\beta$-gal) activity was measured as a control enzyme. This enzyme is also involved in sphingolipid metabolism and is located to the lysosome. Activity was therefore assessed to identify any potential general differences between cellular lysosomal content/enzyme activities in the two cell types. Established fluorescent based enzyme assays were used throughout. [3].

Enzymatic analysis revealed a highly significant difference between the two cell types, i.e. with greater activity for both GBA1 and GBA2 in the neuronal cells. For $\beta$-GAL activity, there was no significant difference [Table 1]. 


\begin{tabular}{|c|c|c|c|}
\hline Enzyme & Astrocytes & Neurons & Significance \\
\hline GBA1 & $145 \pm 8.1$ & $256 \pm 15.0$ & $\mathrm{p}<0.005$ \\
\hline GBA2 & $2.5 \pm 0.2$ & $8.5 \pm 1.4$ & $\mathrm{p}<0.005$ \\
\hline$\beta-G A L$ & $310 \pm 31$ & $380 \pm 25$ & $\mathrm{NS}$ \\
\hline
\end{tabular}

Table 1. Enzyme activity, expressed as $\mathrm{nmol} / \mathrm{h} / \mathrm{mg}$ protein, of GBA1, GBA2 and $\beta-\mathrm{GAL}$ in cultured astrocytes and neurons. Student $t$-test used to assess significance. Data expressed as mean $\pm S E M, n=$ 5 independent culture preparations for neuronal cells and 4 for the astrocytic cell line. NS= no significant difference.

The greater GBA activities in the neuronal cells noted here may reflect greater sphingolipid catabolism and/or a greater requirement for ceramide, the product of GBA activity. Further work is now required to evaluate this suggestion and to consider other factors such as the environment of the lysosomal lumen. This higher neuronal enzyme activity does not appear to be a generalised lysosomal phenomenon as $\beta$-GAL activity was comparable between the neuronal and astrocytic cells.

Whilst human derived cells have been used in this study, a limitation is that this work has been carried out in cell culture. However in support of our findings, Herrara et al., [4] used an in vivo labelling technique to assess rat brain GBA levels and noted greater staining of neurons when compared to astrocytes.

In conclusion, our findings point to a differential GBA activity between astrocytes and neurons. Loss of neuronal cells and/or increased gliosis, from affected brain regions being studied in idiopathic PD, may therefore be a contributing factor to decreased homogenate GBA1 activity and should be considered.

\section{References}

1. Gegg ME, Burke D, Heales SJR, Cooper JM, Hardy J,Wood NW, Schapira AHV, Glucocerebrosidase Deficiency in Substantia Nigra of Parkinson Disease Brains. Ann. Neurol. 2012;72:455-463.

2. Schapira AHV. Mitochondria in the aetiology and pathogenesis of Parkinson's disease. Lancet Neurol 2008;7:97-109.

3. Burke DG, Rahim, AA, Waddington SN, Karlsson S, Enquist I, Bhatia K, Mehta A, Vellodi A, Heales SJR, Increased glucocerebrosidase (GBA) 2 activity in GBA1 deficient mice brains and in Gaucher leucocytes. J Inherit Metab Dis . 2013; 36, 869-872.

4. Herrera Moro Chao D, Kallemeijn WW, Marques ARA, OrreM, Ottenhoff R, vanRoomen C, Foppen E, Renner MC, Moeton M, van Eijk M, Boot RG, Kamphuis W, Hol EM, Aerts JMFG, Visualization of Active Glucocerebrosidase in Rodent Brain with High Spatial Resolution following In Situ Labeling with Fluorescent Activity Based 
$\begin{array}{lllll}\text { Probes. } & \text { PLoS } & \text { ONE } 2017 & \text { 10(9): } & \text { e138107. }\end{array}$

https://doi.org/10.1371/journal.pone.0138107 